Arteterapia. Papeles de arteterapia y educación para inclusión social ISSN: $1886-6190$

\title{
¿Quién soy?: análisis de los estereotipos de género entre distintas culturas a través de la exploración de sus dibujos e historias ${ }^{1}$
}

\author{
Teresa Fernández de Juan²; Iyamira Hernández Pita ${ }^{3}$
}

Recibido: 17 de diciembre de 2015 / Aceptado: 3 de julio de 2016

Resumen. El estudio que se presenta permite, a través de la técnica del dibujo y de sus historias, identificar cómo se edifican los constructos sociales del condicionamiento de género, en grupos de dos contextos culturales (Cuba y México). Los cuales son reproducidos de generación en generación y expresados en los comportamientos de la vida cotidiana. Además, se pretende facilitar la sensibilización y la concienciación del problema con un enfoque socioeducativo de la perspectiva de género. Al contrario de lo esperado, los resultados destacan, sobre todo, las igualdades en la reproducción de estos estereotipos entre las muestras educativamente similares de ambos países.

Palabras clave: Estereotipos; género; dibujo; análisis con historias; comparaciones por países.

\section{[en] Who am I?: Analysis of gender stereotypes between different cultures through the exploration of their drawings and stories}

\begin{abstract}
The study presented here allows, through drawing and stories, identify different cultural groups how to build social constructs of gender conditioning, reproduced from generation to generation and behaviors expressed in everyday life. In addition to facilitating the work of sensitization and awareness of the problem with socio-educational approach gender. Outcomes equalities stand especially in the facsimile of these stereotypes between samples similar educationally Cuba and Mexico, in contrast to
\end{abstract}

Keywords: stereotypes; gender; drawing; analysis with stories; comparisons by countries.

Sumario. 1. Introducción; 2. Dibujarme-dibujarte: experiencias anteriores; 3. Género, violencia y estereotipos: Cuba y México; 4. Metodología; 5. Técnicas e instrumentos; 6. Análisis de los resultados; 7. Conclusiones; 8 . Referencias bibliográficas

1 El presente artículo forma parte de un proyecto mucho más extenso sobre el mismo tema. Su primera parte fue presentada en Fernández y Hernández (2012).

2 Doctora en psicología y especialista en género, violencia, musicoterapia y arteterapia. Profesora-investigadora titular del Departamento de Estudios Culturales de El Colegio de la Frontera Norte, Tijuana, México.

E-mail: teresaf@colef.mx, teruquilinda3@yahoo.com.mx

E-mail: louis.assierandrieu@sciencespo.fr

3 Maestra en sociología y especialista en género y violencia. Profesora auxiliar e investigadora agregada del Centro de Salud Mental de Playa, Cuba.

E-mail: arimayi@infomed.sld.cu,censam@infomed.sld.cu 
Cómo citar: Fernández de Juan, T., Hernández Pita, I. (2016) ¿Quién soy?: Análisis de los estereotipos de género entre distintas culturas a través de la exploración de sus dibujos e historias, en Arteterapia. Papeles de arteterapia y educación para inclusión social 11, 111-126.

\section{Introducción}

¿Quién soy? es la pregunta que organiza nuestra subjetividad al vivir. Y, al vivir, la respondemos, tenemos identidad [...] ¿Quién soy Yo y quiénes son los otros? [...] La identidad de los sujetos se conforma a partir de una primera gran clasificación genérica (Lagarde, 1990).

El arteterapia en general y el dibujo en particular permiten manifestar pensamientos, ideas y actitudes que subyacen en nuestro imaginario social. De ahí que Malchiodi (2010) sustente que su práctica brinda una oportunidad para pronunciarse con imaginación, autenticidad y espontaneidad.

Este medio de comunicación simbólica se esgrime como un importante instrumento para que las personas puedan construir (y/o reconstruir) tanto su identidad como su pertenencia grupal. Y, si al arteterapia le añadimos un enfoque de género, ayuda a muchas mujeres a entender muchos aspectos de su vida, distinguir sus problemáticas y reconocer su igualdad de derechos y de trato con los hombres como bien plantea Hauser (2013: 34),

En este sentido, Hogan (1997), en Feminist approaches to art therapy, enfatiza que los conceptos atribuidos al género están emparentados con la lucha por la supremacía en una comunidad en particular, por lo que, lejos de mostrarse como una entidad fija y dependiente de los aspectos físicos del cuerpo, su significado quedará siempre abierto al desafío, de forma que tanto la hegemonía como sus rivales habitarán en sus representaciones.

Pascual de Lucas (2012), a partir de la serie "Fotogramas Sin Título" de Cindy Sherman, señaló el hecho de que las imágenes ficticias recrean "todos los posibles argumentos en que una mujer puede verse envuelta; los estereotipos de su representación de lo femenino" (pp. 23-24). Por lo cual, al autorretratarse bajo esas figuras, resulta evidente la manera en que la propia identidad se encuentra sometida al imperio de los estereotipos construidos social y colectivamente, donde además interviene la mirada del otro para definir los papeles que a uno le es dado representar.

Es por ello que las técnicas del dibujo, en sus distintas manifestaciones y según sus propósitos, se convierten en herramientas vitales, no sólo de tratamiento, sino también de diagnóstico.

En cuanto a la sexualidad, en términos generales, ésta confiere ciertos comportamientos, prácticas y hábitos que involucran el cuerpo, "pero también designa relaciones sociales, ideas, moralidades, discursos y significados socialmente construidos. [Su] estudio se inicia, al menos para México, muy recientemente, y poco se ha dado cuenta de los significados en torno a la sexualidad y su construcción cultural en relación con lo masculino y lo femenino dentro de relaciones de poder inequitativas" (Villaseñor y Castañeda, 2003: 45).

Por otro lado, la masculinidad como categoría social, está constituida por presupuestos socioculturales sobre ideales y estereotipos tanto de género como de 
sus relaciones, los cuales contribuyen a la construcción del imaginario subjetivo de la representación social y de la manera de ser y de relacionarse de hombres y mujeres (Cf Tuñón y Tinoco, 2009).

De acuerdo con Vélez (2011), cabe destacar que los preceptos de masculinidad y feminidad se encuentran rígidamente insertados en la mentalidad de cada sexo en particular y también en relación con el sexo opuesto: por ejemplo, las mujeres tienen un concepto de masculinidad determinado, así como lo poseen los hombres acerca del comportamiento que se espera de una fémina.

De tal forma, debido a que vivimos en una cultura de estereotipos sexistas en los que aparentemente se privilegia al hombre sobre la mujer, dichos estereotipos afectan negativamente a ambos géneros, al constituir patrones o paradigmas divisionistas que no permiten el descubrimiento, el desarrollo y la expresión de cualidades y valores propios del ser humano sin distinción de sexo.

Como señala Bourdieu (1996) en La dominación masculina:

El sexismo [...] busca atribuir diferencias sociales históricamente construidas a una naturaleza biológica $[\mathrm{y}$ ] de todas las formas de esencialismo es la más difícil de desarraigar. El trabajo milenario de socialización de lo biológico y de la biologización de lo social, al revertir la relación entre causa y efecto, la hace aparecer [como] una construcción social naturalizada (p. 28).

Si para el mundo del varón es importante la agresividad o la competencia, se le enseña también todo lo relacionado con ser fuerte: no llorar, no manifestar ternura, no mostrar inseguridad, etc. Lo mismo sucede en la educación de la mujer, sólo que con los valores y los roles invertidos: se le enseña a ser tierna, maternal y cuidadosa; se le dan muñecas/os o elementos que pueda cuidar, lavar, vestir o pasear; se le enseña a ser receptiva a las demandas de los otros a través de juegos que la inicien en las tareas domésticas; se le estimula a que acate, escuche, acepte y cultive emociones "femeninas"; puede llorar pero no agredir (Sanz, 1997; Proveyer, 2008).

Dentro de las teorías multifactoriales, la identidad de género se refiere al sentido básico de ser hombre o mujer implicando, como bien refiere Spence $(1993)^{4}$, a una conciencia y aceptación del sexo biológico.

En cuanto a la identidad de las personas, representa el conjunto de sentimientos, fantasías y pensamientos materializados a través de conductas y actitudes que, tarde o temprano, se consolidan en rasgos o estilos y se manifiestan en los roles a desempeñar como hombre o como mujer dentro de cada sociedad particular.

Bajo una postura más sociológica, Parsons (1968) conceptualiza a la identidad como un sistema central de significados de una personalidad individual que va a orientar de manera normativa y a dar sentido a la acción de las personas. Dichos significados "surgen en relación estrecha con la interiorización de valores, normas y códigos culturales, que son generalizados y compartidos por un sistema social" (Rocha, 2009: 253). Por lo tanto, la definición que una persona hace de sí misma

4 Quien trabajó en "Gender-related traits and gender ideology: Evidence for a multifactorial theory" con una muestra de estudiantes compuesta por 221 mujeres y 95 hombres, midiendo atributos personales, medidas de género y actitudes ante el rol sexual, entre otros. 
no sólo se deriva de su interacción cotidiana, de cómo se observa y de cómo actúa, sino de todos los aspectos que cultural y socialmente internaliza en torno a su yo.

Y la cultura, entonces, se convierte en otro ingrediente fundamental del desarrollo de una identidad en la medida en que se encuentra indisolublemente ligada a su carácter histórico y social. De tal manera, "la forma en la cual una persona llega a definirse a sí misma y concibe su propio 'yo', no es una situación estática e inamovible y mucho menos universal, sino que está supeditada a las condiciones históricas de un momento determinado y, a su vez, a la variabilidad intercultural" (Rocha, 2009: 251).

\section{Dibujarme-dibujarte: experiencias anteriores}

Entre los estudios previos que abordan el análisis de dibujos, encuestas e historias para representar los estereotipos de género se encuentran los siguientes:

La socióloga Gilligan (1994) realizó un análisis de las diferencias de género a partir de las imágenes que los hombres y las mujeres tienen de sí mismos y de sus logros. Para su investigación aplicó 200 entrevistas a adultos en Estados Unidos dirigidas a conocer su concepción de "lo que está bien o mal moralmente". Gilligan concluyó que las mujeres se definen a sí mismas en términos de relaciones personales y que juzgan sus logros en función de su capacidad para cuidar a los otros. Los hombres, en cambio, respondieron con ideales abstractos acerca del deber, la justicia y la libertad individual. El rol tradicional que realiza la mujer es el de cuidadora y compañera, pero dichas tareas son a menudo infravaloradas por los hombres, quienes, a su vez, consideran que el énfasis de sus logros está en las maneras de conseguir el éxito individual.

Villaseñor y Castañeda estudiaron a 155 alumnos de secundaria y preparatoria de la zona metropolitana de Guadalajara, México ${ }^{5}$, desde una postura teórico-crítica de género y sociocultural constructivista. Según sus resultados, la masculinidad implica una práctica de violencia que se origina por la invisibilización e influencia social del machismo ("para sentirse más hombre, decir :yo soy el más macho”), la poligamia ("que andan con una y otra y otra”), la falta de educación moral, la cultura de inequidad de género, los patrones familiares de violencia ("los padres muy machistas influyen en sus hijos, éstos tratan de imitar esta imagen machista y violenta”) y la falta de información sexual y sobre la violencia sexual (Villaseñor y Castañeda, 2003: 48).

Campos y Trautner (2004) trabajaron con una muestra de 696 estudiantes (327 del sexo femenino y 369 del masculino) de 11 a 16 años, tanto de Costa Rica como de Alemania; valorando las características del hombre y de la mujer ideal a través de una escala tipo Lickert desarrollada por Gibbons, Brusi-Figueroa y Fisher en 1997. También usaron dibujos para representar esos modelos, realizando una actividad en particular. En sus

5 Compuesto de 6 grupos de hombres y 6 de mujeres. 
conclusiones destacan que, al contrario de lo supuesto, no se hallaron evidencias de que Costa Rica primara como un país fuertemente femenino y Alemania como masculino. Los dibujos de los adolescentes alemanes (varones) fueron más estereotipados por género y mostraron más elementos de maduración física que los de sus iguales costarricenses. Por su parte, los dibujos costarricenses en general muestran el ideal de persona más a menudo dentro de contextos sociales.

Rocha (2009) estudió a 400 hombres y mujeres adultos ${ }^{6}$ a partir de un inventario culturalmente sensible (Inventario Multifactorial de Género) desarrollado en el año 2004 y que integraba cuatro variables fundamentales (roles, rasgos de masculinidad-feminidad, estereotipos de género y actitudes hacia el rol de género), explorando su interconexión. Observó que el tipo de rasgos, las conductas, las motivaciones y las cogniciones que las personas poseían, se encontraban más en consonancia con su propia autodefinición que en función de su sexo biológico.

También se hizo evidente que a pesar de la relevancia del momento histórico y social ${ }^{7}$ (en el caso de México, por ejemplo), aunque de manera general pudiera pensarse que las oportunidades para ambos sexos están cambiando, en la vida cotidiana la visión estereotipada no se ha modificado con la misma velocidad que las transformaciones sociales. Debe considerarse que muchos de los estereotipos con los cuales se reviste la actuación de los individuos se han vuelto universales $\mathrm{y}$, por tanto, indisolubles. Sin lugar a dudas, la tarea de cualquier estereotipo es, entre otras cosas, la de fundamentar y mantener una serie de ideas, creencias y valoraciones que justifiquen las acciones e incluso permitan diferenciar a un grupo de otro.

\section{Género, violencia y estereotipos: Cuba y México}

En cuanto a la situación entre mujeres y hombres que presentan México y Cuba, estudios recientes siguen señalando la presencia del machismo ${ }^{8}$ y la violencia perpetrada hacia las mujeres por parte de los hombres.

En el caso de México, los resultados de la Endireh ${ }^{9} 2011$ a nivel nacional señalaban que $44.9 \%$ de las mujeres mayores de 15 años había sufrido violencia

6 Con el doble de mujeres que de hombres.

7 Rocha y Díaz-Loving (2005), que explican ampliamente el hecho de que cada cultura desarrolle una serie de pautas normativas y significados que delimitan la actuación de hombres y mujeres, exploraron las creencias y valoraciones que actualmente fundamentaban la percepción diferenciada en México. Luego de finalizado el trabajo, percibieron la naturalidad con la que muchas diferencias vivían y se mantenían tanto entre los hombres como entre las mujeres.

8 Por ejemplo, según Aguado y Rogel (2004), "En México, la sexualidad se encuentra fuertemente cargada de significaciones morales y religiosas, con marcadas diferencias de género [que] han sido construidas durante siglos de relaciones sociales y políticas [...] y, en general, los significados construidos obedecen a densos sistemas morales tanto religiosos como seculares" (p. 32).

9 Encuesta Nacional sobre la Dinámica de las Relaciones en los Hogares (ENDIREH). Tuvo como objetivo generar información estadística sobre la frecuencia y magnitud de la violencia de pareja, así como la que experimentan las mujeres en los ámbitos escolar, laboral y comunitario. Esto, con el propósito de coadyuvar a 
por parte de su pareja. Pero en ese mismo año, en el estado de Baja California, el $38.6 \%$ de las mujeres encuestadas mayores de 15 años había sufrido violencia a lo largo de su relación con su última pareja, cifra que ascendió en el estado al $44.9 \%$ en ese rango etario (INEGI ${ }^{10}, 2013$ : 9). También en 2011, de las mujeres que reconocieron haber sufrido violencia por parte de su pareja, el 91.5\% había sido de tipo emocional, el $50.5 \%$ experimentó violencia económica y el $21.1 \%$ y $10.4 \%$ padecieron violencia física y sexual, respectivamente (INEGI, 2013: 11).

En un acercamiento a las raíces culturales de esta problemática, al indagar sobre el sentir y pensar de las mujeres frente a ciertos roles socialmente esperados, en la Endireh 2011 se encontró que, entre las mujeres que sufrieron violencia por parte de su pareja a partir de los 15 años, casi un tercio manifestó estar de acuerdo en que "si hay golpes o maltrato en su casa es un asunto interno, o sea, de familia y que por lo tanto no debía divulgarse". Aproximadamente un séptimo de esta población estuvo de acuerdo en que "una esposa debe obedecer a su esposo o pareja en todo lo que él ordene" y que "es obligación de la mujer tener relaciones sexuales con su esposo o pareja" (16.8\% y $14.7 \%$, respectivamente) Con estos preceptos que "evidentemente" continúan trasmitiéndose de generación en generación, se aprecia la ardua labor que aún tenemos por delante.

Por otra parte, aunque en Cuba los resultados de algunas estadísticas aisladas e investigaciones realizadas demuestran que las mujeres cubanas sufren abusos menos severos y toleran menos tiempo la violencia marital que las de otros países, ${ }^{11}$ aún queda mucho por hacer en la deconstrucción de la cultura patriarcal, sostén de la inequidad que hace posible la violencia de género (Proveyer, 1999: 32). Por lo tanto, entendemos que también aquí existen problemas con los estereotipos que conducen a las diferentes formas de maltrato a la mujer ya descritas en la literatura por parte de otros países. Sin embargo, como se manifiestan de manera poco visible y se practican como parte inherente de la vida cotidiana, al no existir registros nacionales sobre su magnitud, tipos e incidencia, no podemos realizar una comparación válida.

\section{Metodología}

Con el objetivo de identificar los estereotipos de género subyacentes en las imágenes e historias de vida de las representaciones sobre el hombre y la mujer, se trabajó con una muestra de 242 sujetos: 163 mujeres y 37 hombres, 99 nacidos en Cuba y 143 en México, con el mismo nivel de escolaridad y edades entre los 17 y los 46 años. En ambos casos se contempló el trabajar con diferentes contextos socioculturales y al final se realizaba una extensa discusión grupal por equipos,

la conformación del Subsistema de Estadísticas sobre Violencia, dentro del Sistema Nacional de Información Estadística y Geográfica.

10 El Instituto Nacional de Estadística y Geografía (INEGI) es una institución gubernamental de México encargada de realizar los censos poblacionales y económicos. Su trabajo de recopilación de información incluye estadísticas de ocupación y empleo, de violencia intrafamiliar y de pareja, como fundamento para diversos estudios y proyecciones.

11 Debido a factores indudablemente importantes como son su acceso al trabajo asalariado en igualdad de condiciones que el hombre, su fácil accesibilidad al divorcio si ellas así lo deciden, el derecho total que legal y moralmente sienten sobre su cuerpo y su reproducción, y la elevada educación alcanzada, entre otros. 
donde se procedía al análisis de los estereotipos de género que habían representado en sus dibujos sin percatarse de ello. La muestra estuvo distribuida como se muestra en la siguiente tabla:

\begin{tabular}{|l|l|c|l|}
\hline \multirow{2}{*}{ País } & \multicolumn{2}{|c|}{ Sexo } & \multirow{2}{*}{ Total por país } \\
\cline { 2 - 3 } & Femenino & Masculi & \\
\hline Cuba & 84 & 15 & 99 \\
\hline México & 105 & 38 & 143 \\
\hline $\begin{array}{c}\text { Total por } \\
\text { sexo }\end{array}$ & 163 & 37 & $\mathbf{2 4 2}$ (total global) \\
\hline
\end{tabular}

Fuente: Elaboración propia (2013).

Estos grupos provenían de diversas instituciones y regiones, tanto de México como de Cuba. A pesar de sus diferentes procedencias, el nivel de estudios de los participantes fue de licenciatura, buscando nivelar sus condiciones para obtener igual concepción acerca de los derechos de la mujer y de diversos aspectos de género.

La intención era explorar si existían diferencias entre ambos países, pues, aunque comparten muchas similitudes producto de las diversidades culturales, también presentan desigualdades en lo que respecta al papel asumido por la mujer en el espacio público, así como en dogmas, paradigmas y aspectos relacionados con la educación sexual y de empoderamiento femenino recibidas.

Nuestra hipótesis consistió en encontrar un espectro de equidad en lo que respecta a las concepciones, tareas, deberes y derechos de los hombres y de las mujeres debido a su nivel de estudios y proyectos futuros; especialmente entre las cubanas, por las características sociales y legales que "se supone" las empoderan más en su país.

Para este estudio descriptivo transversal y aplicado nos apoyamos en la metodología cualitativa, con un diseño de casos múltiples. Se usó la Investigación Acción Participativa (IAP ${ }^{12}$ ), que nos permitió legitimar las acciones, promover la reflexión y así lograr una sensibilización frente al tema de investigación que nos ocupaba.

\section{Técnicas e instrumentos}

Se utilizaron técnicas participativas de exploración, esclarecimiento, confrontación y orientación apoyadas en dinámicas grupales empleando el dibujo y su historia como técnica proyectiva para sensibilizar desde lo cognitivo y vivencial.

12 Metodología de la investigación cualitativa que potencia la participación consciente de los sujetos en el proceso de cambio, desarrollando la autonomía y la búsqueda de soluciones desde sus propias alternativas y que jerarquiza sus necesidades y recursos para lograrlo, según el contexto de actuación. 
A través del trabajo colectivo (con equipos aleatoriamente formados con la participación de ambos sexos, de 3 a 6 personas) "por separado" en cada contexto cultural, esta técnica en particular se llevó a cabo en una sola sesión, que en cada caso comprendió un periodo de 4 a 5 horas. Después de llevar a cabo técnicas de desensibilización y cohesión grupal, el siguiente paso fue entregarle a cada participante hojas grandes y rotuladores de colores, con la consigna de dibujar a un hombre y a una mujer ( $\sin$ importar el orden) y elaborar una historia de cada uno/a de ellos/as, incluidos sus datos personales (ejemplo: nombre, edad y forma de vida, significado que tienen en las relaciones con los otros y particularmente con el otro sexo, etc.).

Al final, un miembro de cada grupo exponía la historia y el dibujo al resto de los participantes, quienes podían hacer preguntas sobre el porqué de esa representación y no otra, permitiendo la deconstrucción colectiva de los estereotipos femeninos y masculinos según el contexto histórico concreto.

Para la interpretación del dibujo se trabajó con las pautas del reconocido estudioso de las masculinidades Kaufman (2010); quien ha validado esta técnica con un carácter fenomenológico haciendo uso del interaccionismo simbólico ${ }^{13}$ que facilita la identificación de símbolos, códigos y significados que responden al comportamiento frente a un fenómeno determinado. En este caso, a los estereotipos de la construcción de la feminidad y de las masculinidades.

Se utilizó durante todo el proceso la observación científica, que permitió detectar manifestaciones de las funciones y estilos de la comunicación grupal, sin previa estructuración. Por lo que se tomó nota de conductas observadas, de las expresiones asociadas al tema, los intereses que se manifestaban así como los diferentes propósitos entre los miembros, las muestras de compatibilidad y de incompatibilidad. También se apuntaron las formas en que se desenvolvieron los integrantes del grupo, los símbolos y códigos con los que nominalizaban las categorías asociadas a la construcción psicológica, biológica y sociocultural del género y a su relación con los comportamientos violentos. Se prestó especial atención al clima psicológico durante el proceso grupal, a la postura asumida durante el intercambio de opinión para construir las figuras y a las expresiones corporales, así como al comportamiento asumido durante el análisis de los roles genéricos y de sus expresiones desde el imaginario social.

\section{Análisis de los resultados}

\section{México y Cuba}

En ambos países, a pesar de confluir diferentes regiones, costumbres, tradiciones e identidades socio-históricas y culturales que constituyen puntos de desencuentros, se muestra cómo perviven las expresiones estereotipadas asociadas a la construcción de las feminidades y las masculinidades:

Aparecen indistintamente nuevos constructos sobre la imagen del hombre: los llamados metrosexuales, quienes asumen nuevos atributos, "zarcillos, alisado del cabello, depilado del pecho y los brazos, afeitado

13 Esto no es más que el análisis de los significados y su repercusión en la interacción social, así como en la relación que tienen las creencias con los actos. (Cf Mills, C. 1961) 
de las cejas". Se aprecia esto como forma de autocuidado máximo entre ellos. Esto unido a una gran preocupación por los rasgos de fortaleza física que definan su cuerpo, representen su virilidad y reafirmen su masculinidad. El hombre suele ser deportista y/o casi siempre se ejercita para definir bien sus músculos. En cuanto al carácter, son muy agradables, buenos compañeros de trabajo, poseen buenas relaciones con todos, son divertidos y, sobre todo, son muy modernos. En general, todos tienen buena apariencia, cuidan mucho su físico y se ven ejercitados y musculosos en los dibujos (ver figuras 1 y 2).

No se observaron diferencias notables entre las mujeres mexicanas y las cubanas. A pesar de los avances de las mujeres en Cuba, aún se mantienen, incluso entre las propias féminas, los estereotipos de "mujermadre, coqueta, preocupada por su apariencia física para gustar a los hombres" $\mathrm{y}$, a pesar de estar en muchos casos emancipada económicamente y con caracteres concretos de empoderamiento académico, con proyectos a largo plazo, sobre todo en el ámbito profesional, estos se vinculan sobre todo a los momentos previos al esperado matrimonio formando una familia con hijos. E incluso en otros casos, mantienen económicamente a la pareja para que esta acabe de estudiar. Lo cual muestra un curioso efecto de emancipación, ya que esto no las hace independientes en su imaginario emocional, pues con gran naturalidad cargan con la responsabilidad "incluso económica" de su pareja masculina.

Continúan presentes los cánones de belleza que asfixian la singularidad de la mujer y refuerzan los estereotipos de la feminidad: pestañas largas, pelo largo, senos y caderas pronunciados, zarcillos, brazaletes, cadenas en el pecho, lunares, labios y uñas pintadas, ropa ajustada, buena figura, ropas con un color considerado femenino y otros aspectos en su vestimenta que las destacan, adornos, carteritas colgando de sus muñecas (ver figuras 3 y 4). $\mathrm{Y}$ en los casos en que en lugar de pintar mujeres, pintaban niñas, estas eran frágiles, indefensas, lindas, inocentes, de colores muy femeninos, con flores y mariposas. En cuanto al carácter, aunque a veces son extrovertidas, suelen tener menos relaciones, pertenecer a grupos más cerrados, asistir fuera de los estudios a pocas actividades, etc.

Se ve como natural que los hombres no suelan tener una pareja estable y si la tienen, que mantengan a su vez varias relaciones no formales. Las mujeres conservan una sola pareja por años, o no piensan en eso mientras estudian, pero luego encontrarán al hombre adecuado y formarán una familia. Es muy notable cómo resulta inaceptable la "doble moral" en las mujeres: Estas resultan muy mal vistas entre ellas mismas (en la forma de ser dibujadas y tratadas) por tener una vida "libertina" sexualmente (pues chulean al marido para mantener al amante más joven, o parte de su dinero lo emplean para darle gustos a su amante joven, y decimos amante porque para él no es única sino compartida siempre). O resultan ser todo lo contrario, según el patrón arcaico tradicionalista: tímidas, convencionales, educadas, decentes y de padres exigentes. Incluso, 
cuando una de ellas por fin tiene relaciones con el novio, es muy criticada en la historia pues, por no ser virgen, aunque defendía serlo, le contagió al novio una enfermedad de trasmisión sexual ${ }^{14}$. De hecho, algunas son calladas, "decentes" e introvertidas de día, y por la noche... Una es una bailarina exótica y sensual, otra está en una banda de rock, $\mathrm{y}$, en más de un caso (en ambos países) se hacen pasar por "vírgenes" ante su novio, pero en realidad no lo son, por lo cual se burlan de ellas o las culpan en la propia historia ${ }^{15}$.

También se continúan observando tendencias machistas en los tipos de trabajos escogidos (las mujeres: pintoras, modelos, educadoras infantiles, azafatas, maestras; los hombres: instructores de gimnasia, deportistas, jugadores de fútbol, están con su monopatín, trabajan en informática), y en la forma en que se distribuyen los roles dentro del hogar, con conductas contradictorias dentro de este desarrollo como, por ejemplo: la mujer debe ser una triunfadora en el trabajo y en los estudios, pero sin descuidar nunca su aspecto físico (acorde con lo aprendido como seres sensuales dispuestos a complacer al otro sexo) y a la vez deben ocuparse de un hombre que "está por debajo de ellas en sus niveles educativos o profesionales (al contrario de lo esperado por los patrones de género, donde el hombre es el proveedor máximo o hasta único)", asumiendo como antes los roles tradicionales de cuidadora.

Las mujeres, por ser jóvenes (aunque ya estén acabando la universidad) suelen ser solteras, viven con su familia y varias tienen mascotas. La mayoría de los hombres, en cambio, ya viven solos o son ayudados por sus padres. Cuando una mujer vive sola y no tiene pareja, se cuestiona su sexualidad.

En ambos talleres se advierte que al dibujar intentan, en algunos casos, pintar al hombre y a la mujer ideal, o sea, lo que les gustaría encontrar o ser. Y además, que es mucho más difícil hacer al hombre: "en la mujer casi se da sola la historia luego de dibujarla y en la del hombre se encuentran pocos datos". También es importante apuntar que siempre hubo mayoría de mujeres en los grupos.

En el subgrupo extra (compuesto por alumnos de preparatoria de una universidad privada de Tijuana) llama la atención el énfasis que hacen en las cosas materiales, sobre todo los varones (que componían la mayoría); el hecho de que poseen ropa y materiales deportivos de marca, tienen dinero por cualquier vía, y las mujeres están muy resaltadas en sus caracteres sexuales $^{16}$. Otro atributo que sólo se da en ese subgrupo es la

14 No se tiene en cuenta en absoluto la responsabilidad compartida que ambos tienen en cuanto al cuidado de las relaciones sexuales.

15 Como bien expresara Marcela Lagarde (1990: 7): "La sexualidad femenina cambia. Por primera vez se separa la procreación del erotismo, y la brecha milenaria entre sexualidad procreadora y sexualidad erótica, que escinde a la mujer como género, tiene la posibilidad de desembocar en una identidad cohesionada, integrada. Pero las mujeres saben y no se equivocan, que su ser les es ajeno, que su cuerpo y su subjetividad ha sido ocupado por la sociedad para los otros" (negrita de las autoras).

16 Los hombres, como en el resto, se dibujan muy musculosos. Debemos recordar que en esta edad es cuando afloran con más fuerza las hormonas (Cfr. Bhalla, s/a). Los adolescentes tempranos pueden sentir preocupación por estos cambios y por la forma en que otras personas los percibirán. Este también puede ser un 
presencia de ojos azules y pelo rubio en los hombres como signo de hermosura (prejuicio mucho más arraigado en México que en Cuba como ideal de belleza).

\section{Rasgos socioculturales que sobresalen como elementos diferenciadores entre ambos países}

En Cuba:

Es importante observar cómo a través de las historias se evidencia la devaluación que existe entre la población respecto al rol profesional, tanto de los hombres como de las mujeres, por no estar bien remunerados a consecuencia de una inestabilidad en la estructura económica del país. Esto equivale a un desequilibrio de poder presente en las relaciones sociales que se establecen en ese contexto socio-histórico actual.

Aparecen factores materiales realzados que, por su carencia en el país y su dificultad de acceso como propiedad individual, le otorgan un prestigio a quien los posee, que suele tomarlos como un factor de seducción: El que un hombre tenga un coche (no importa el año ni la marca, ni siquiera si usa el de sus padres); el que una mujer trabaje en un grupo de apoyo al turismo (lo cual "como bien se expresa en esa historia" le permite tener, a pesar de sus limitaciones materiales, más libertad sexual, mayores facilidades de vida y un mayor atractivo para mantener a su pareja, más joven que ella y que es su amante), y hasta el hecho de poseer una bicicleta propia como medio de transporte para resolver sus necesidades más urgentes.

En más de una historia está "de moda" el que un hombre mantenga una relación amorosa (en un plano no formal) con una mujer mayor, para que le dé experiencia y facilidades económicas.

Mientras tanto, en el caso de México:

Es muy común en las historias que se señale el lugar de origen de distintas regiones y hasta países, así como el deseo y la opción de viajar, esto en todas las provincias y lugares y "sobre todo" entre las mujeres, lo cual no ocurrió en las historias de Cuba. Esto indica, por un lado, la importancia que se otorga en México al factor de migración interno (mucho más que en la Habana, Cuba, donde también existe), y por el otro lado, la posibilidad de viajar a otros países (aunque sea con una beca, por lo que pueden emprender con naturalidad sus estudios de postgrado, $u$ otras opciones), aspecto muy difícil de llevar a cabo en Cuba y "por ende" poco planeado en sus historias concretas de vida.

También aparece en uno de los relatos de Tijuana cómo una novia trafica con sus órganos, lo que destaca una triste realidad actual de la que Tijuana llegó a tener uno de los peores estigmas, aunque en la actualidad se supone está controlada, al menos visiblemente. 


\section{Conclusiones}

El modelo de la cultura patriarcal y su transmisión inter-generacional, a pesar del tiempo trascurrido y los esfuerzos que en varios países se han hecho (en este caso en varias regiones de México y en Cuba) mantiene una vigencia y una repetición de mensajes que aún legitiman con enorme peso esos modos de comportamiento como adecuados. En este sentido, pudimos observar que, al menos en lo que respecta a las muestras utilizadas en nuestro trabajo (que además eran de un nivel educativo alto), más allá de cambios en la sociedad, los estereotipos de masculinidad y feminidad de la ideología genérica patriarcal aparecen inalterados y totalmente vigentes. Como bien señala Marcela, quien además apunta: "Todavía estructura identidades. Es una ideología fosilizada, porque expresa y sintetiza separaciones simbólicas inmutables que no corresponden a la complejidad genérica de los sujetos" (Lagarde, 1990: 6).

El estereotipo femenino (Giddens, 1994: 7) ${ }^{17}$-cuya investigación en los medios comenzó en la década de los setenta, con el abuso de la exhibición del cuerpo femenino como objeto sexual en los mensajes publicitarios-, continúa influyendo en la mentalidad estereotipada de las muestras de ambos países y con independencia de la región de origen. Sigue siendo importante para estas mujeres el ser atractiva físicamente, mantenerse jóvenes y ofrecer un apoyo incondicional al hombre. Aunque se lleva a cabo una revolución en el plano sexual con evidentes diferencias con épocas anteriores, no se concibe moralmente, ni siquiera en el imaginario de las propias mujeres, emancipadas económicamente y con posibilidades de llevar una vida libre de prejuicios ni ataduras. Como bien planteara Tessa Dalley (1987), el símbolo surgido en las imágenes no expone aparentemente una "preocupación inmediata", sin embargo, se acomoda dentro "de una preocupación de más envergadura", mostrándose como una pista a seguir. Consecuentemente, el arteterapia invita a una interiorización sobre uno/a mismo/a, que facilita un acercamiento a esa compleja forma surgida y posibilita la confrontación y el diálogo con lo creado (Cassasolar y Sánchez, 2011).

A su vez, es de destacar cómo hallamos en este trabajo variantes en el estereotipo masculino: La necesidad de recalcar la modernidad y el físico atractivo del hombre y esta preocupación por su auto-cuidado, su musculatura excesiva y su afán deportivo, e incluso la incorporación de aspectos metrosexuales, sin detrimento de su imagen de masculinidad. Este aspecto no esperábamos encontrárnoslo en el presente estudio. Es curioso que, además, el hombre asuma con naturalidad no ser en tantos casos el responsable de la economía de la pareja, aspecto que a su vez se adjudica ahora en mayor medida la mujer. El hombre está más cómodo, tiene menos responsabilidades y se ocupa de mantener una imagen espectacular, cosa que también debe seguir haciendo la mujer aunque ahora incorporada como cuidadora máxima del sustento económico de ambos si fuera necesario. Por lo tanto, sigue cobrando una triste vigencia lo ya planteado por Marcela Lagarde en el siglo pasado (1990: 8- 9):

Ahora de manera unilateral las mujeres están en ambos espacios. En la

17 Y de lo cual también se habla en Suárez (2007). 
vida privada y doméstica su trabajo es invisible (Larguía, 1977) [...]. Ya no corresponde a la división sexual tradicional, que colocaba (ideológicamente) a las mujeres en la reproducción y a los hombres en la producción. Las mujeres ocupan espacios, [...] pero lo hacen en situación de inferioridad y de no pertenencia, todavía como extranjeras. La síntesis sincrética de identidades en transformación constituye y organiza la subjetividad de estas mujeres que [...] emprenden nuevas actividades, nuevas relaciones, nuevas formas de comportarse, trabajan por doble partida y se desenvuelven en una doble vida, en un desdoblamiento que cada una tiene que elaborar subjetivamente e integrar en su identidad. [Su] presencia en los ámbitos propios y en los que tradicionalmente eran masculinos, y la re-significación ideológica y política (jurídica, mítica), hace que el mundo se feminice. Esto se combina con la desaparición de grandes áreas de la masculinidad de los hombres, y con la reconversión de las mujeres para sustituirlos y se crean más espacios exclusivamente femeninos en el mundo patriarcal.

La contradicción central en este nivel es de orden político: las mujeres realizan hechos de vida propios y para los otros y crean cada vez más riqueza social, cultural y política, y ello no conlleva una directa creación de poderes legítimos ni ejercidos a plenitud por ellas [...]. Los hombres han disminuido su condición genérica, son hoy más carentes pero valen igual. Las mujeres hemos enriquecido nuestra condición genérica [pero] este hecho no sólo no es reconocido, sino que valemos menos, tasadas con las viejas medidas de la feminidad patriarcal ${ }^{18}$.

\section{Referencias bibliográficas}

Aguado E. y Rogel, R, (2004) Educación, escuela y construcción de la sexualidad en grupos indígenas, Educación y Ciencia, Universidad Autónoma de Yucatán, vol. 8, núm. 15 , pp. 27-43.

Bem, S (1981) Gender schema theory: a cognitive account of sex typing, Psychological Review, vol. 88, núm. 4, pp. 354-364.

Bhalla, S., (s/a) Consejos según la edad: Cómo educar a su hijo adolescente, One Tough Job, Boston, Massachusetts, Children's Trust Fund of Massachusetts, en: http://espanol.onetoughjob.org/consejos-segun-la-edad/12-a-15/como-educar-a-suhijoa-adolescente, consultado el 22 de abril de 2013.

Bordieu, P, 2005, La dominación masculina, CEME- Centro de Estudios Miguel Enriquez, Archivo Chile, pps: 41, Recuperado de:

http://www.archivochile.com/Mov_sociales/mov_mujeres/doc_gen_cl/MSdocgenc1001 1.pdf., consultado el 31 de marzo del 2013

García R. y SÁNCHEZ-GUZMÁN, S. (2011). Arteterapia y subjetividad femenina: construyendo un collage. Arteterapia: Papeles de arteterapia y educación artística para la inclusión social 36, 87-103.

18 Negrita de las autoras. 
Campos, D., y Trautner, H. (2004). El hombre y la mujer ideal según adolescentes en Costa Rica y Alemania. Revista Latinoamericana de Psicología, 36(3), 471-482. Bogotá: Fundación Universitaria Konrad Lorenz.

Dalley, T. (1987). El arte como terapia. Barcelona: Herder, Biblioteca de Psicología.

Endireh 2011 Encuesta Nacional sobre la Dinámica de las Relaciones en los Hogares 2011, edit por la INEGI, Recuperado de: http://www.inegi.org.mx/est/contenidos/proyectos/encuestas/hogares/especiales/endireh /endireh2011/default.aspx, consultado el 6 de febrero del 2015

Fernández, T. y Hernández, I. (2012). Estudio del dibujo de la figura humana como elemento explorador de estereotipos en las relaciones de género y de aspectos culturales. En M. A. Padilla (Ed.), Avances en la investigación científica de los miembros del Sistema Mexicano de Investigación en Psicología (SMIP), Universidad Autónoma de San Luis Potosí/Universidad de Guadalajara. Recuperado de http://www.organicaeditores.mx/biblioteca/smip2012/contenido/resumenes3.html

García R. y Sánchez-Guzmán, S. (2011). Arteterapia y subjetividad femenina: construyendo un collage. Arteterapia: Papeles de arteterapia y educación artística para la inclusión social 36, 87-103.

Gilligan, C. (1994). La moral y la teoría. Psicología del desarrollo femenino. México, D. F.: Fondo de Cultura Económica.

Hauser, J. (2013). Inclusión social a través del arteterapia con enfoque de género, experiencias con migrantes latinoamericanas. Arteterapia: Papeles de arteterapia y educación artística para la inclusión social, 8. Universidad Complutense de Madrid.

Hogan, S (1997) Feminist approaches to art therapy, Nueva York, Routledge.

INEGI, 2013, Panorama de violencia contra las mujeres en Baja California. ENDIREH 2011, Aguascalientes, México, Instituto Nacional de Estadística y Geografía (INEGI)/Instituto de la Mujer del Estado de Baja California.

Kaufman, M. (2010). Los hombres, el feminismo y las experiencias del poder entre los hombres. En Informe mundial sobre violencia y salud (soporte digital), Diplomado Nacional de Violencia (pp 1-3). La Habana: Centro Nacional de Educación Sexual.

Lagarde, M. (1990). La identidad femenina. México, D. F.: Comunicación, Intercambio y Desarrollo Humano en América Latina.

Mills, C (1961) . The Sociological Imagination, Nueva York: Oxford University Press, 1959. Trad, castellana: La Imaginación Sociológica, México: FCE.

Parsons, T (1968) The position of identity in the General Theory of Action, C. Gordon y K. Gergen, edits., The self in social interaction, Nueva York, Wiley, pp. 16-23.

Pascual , M (2012) Arteterapia en femenino, Trabajo fin de master, curso 2011-2012, Universidad Autónoma de Madrid, Recuperado de http://eprints.sim.ucm.es/17671/1/Arteterapia_en_femenino.pdf., consultado el 31 de marzo del 2014

Proveyer C. (1999) La violencia ejercida sobre mujeres españolas y cubanas, Revista Cubana Sexología y Sociedad, vol. 5, núm. 12, pp. 31-35.

Proveyer C (2008) Nombrar lo innombrable: La violencia sutil en la relación de pareja, Boletín No a la violencia, La Habana, Cuba, Editorial SEMlAC, junio de 2008.

Rocha T. (2009). Desarrollo de la identidad de género desde una perspectiva psico-sociocultural: Un recorrido conceptual. Interamerican Journal of Psychology, 43(2), 250259. Recuperado de http://pepsic.bvsalud.org/scielo.php?pid=S003496902009000200006\&script=sci_arttext, consultado el 30 de abril del 2014 
Rocha T y Díaz-Loving, R (2005) Cultura de género: La brecha ideológica entre hombres y mujeres Anales de psicología, vol. 21, nº 1 (junio), 42-49 Servicio de Publicaciones de la Universidad de Murcia.

Sanz, F (1997) Psicoerotismo femenino y masculino. Para unas relaciones, autónomas y justas, Barcelona, Editorial Kairós.

Suárez, J (2007) Estereotipos de la mujer en la comunicación, Mujeres en Red, periódico feminista, Recuperado de http://www.mujeresenred.net/IMG/pdf/estereotipos.pdf. consultado el 2 de febrero del 2013

Spence, J. (1993) Gender-related traits and gender ideology: Evidence for a multifactorial theory", Journal of Personality and Social Psychology, vol. 64, núm. 4, abril, pp. 624635.

Tunón, E., y Tinoco, R. (2009), ¿Historia no es destino? Masculinidades juveniles tabasqueñas contemporáneas. La Ventana, 3(29), 32-66.

Villaseñor-Farías, M., y Castañeda, J. (2003). Masculinidad, sexualidad, poder y violencia: Análisis de significados en adolescentes. Revista Salud Publica de México, 45, 44-57. Recuperado de http://www.scielosp.org/pdf/spm/v45s1/15445.pdf, consultado el 1 de enero del 2013

Vélez, L, (2011), "Representaciones y estereotipos femeninos en los medios de comunicación", en XII Encuentro Internacional de Centros de Cultura, UPAEP, en http://www.upaep.mx/micrositios/12encuentro/Ponencia\%20Lilia\%20Velez.pdf, consultado el 22 de abril de 2013.

\section{Figuras}
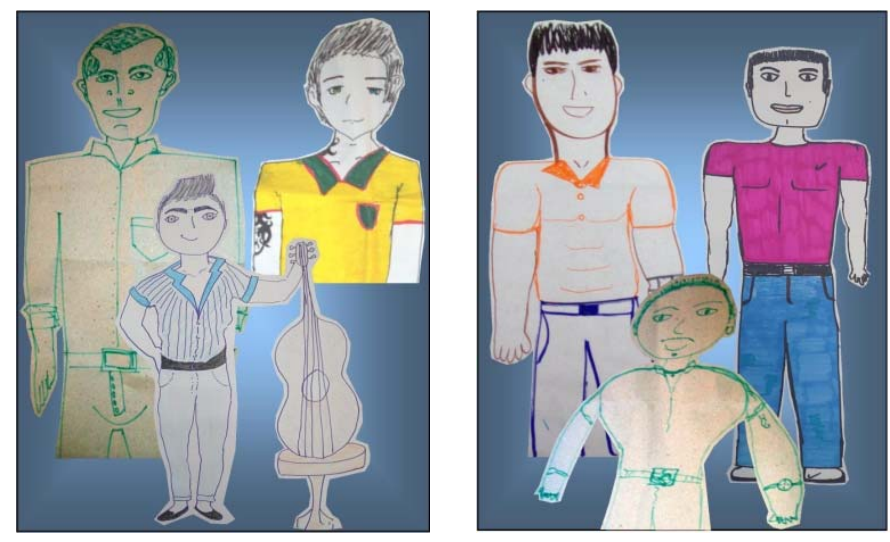

Figuras 1 y 2. Fragmentos que muestran la figura estereotipada de los dibujos masculinos. 

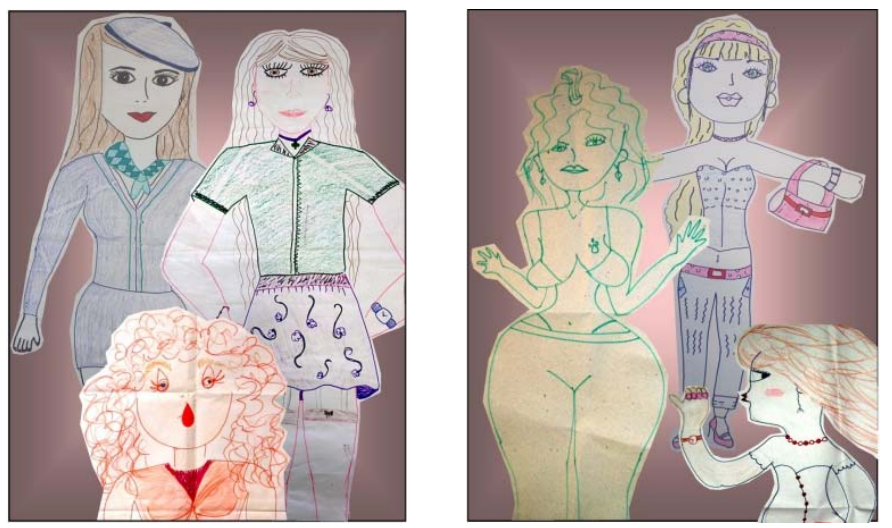

Figuras 3 y 4 . Fragmentos que muestran la figura estereotipada de los dibujos femeninos. 